\title{
Gold kiwifruit consumed with an iron-fortified breakfast cereal meal improves iron status in women with low iron stores: a 16-week randomised controlled trial
}

\author{
Kathryn Beck*, Cathryn A. Conlon, Rozanne Kruger, Jane Coad and Welma Stonehouse \\ Institute of Food, Nutrition and Human Health, Massey University, Private Bag 102 904, North Shore Mail Centre, \\ 0745 Auckland, New Zealand \\ (Received 25 March 2010 - Revised 5 July 2010 - Accepted 12 July 2010 - First published online 23 August 2010)
}

\section{Abstract}

Ascorbic acid, and more recently, the carotenoids lutein and zeaxanthin have been shown to enhance Fe absorption. However, it is not clear whether Fe status improves when foods high in ascorbic acid and carotenoids are consumed with Fe-fortified meals. The present study aimed to investigate whether consuming high $v$. low ascorbic acid-, lutein- and zeaxanthin-rich fruit (gold kiwifruit $v$. banana) with Fe-fortified breakfast cereal and milk improved Fe status in women with low Fe stores. Healthy women aged $18-44$ years $(n$ 89) with low Fe stores (serum ferritin $\leq 25 \mu \mathrm{g} / \mathrm{l}$ and $\mathrm{Hb} \geq 115 \mathrm{~g} / \mathrm{l}$ ) were randomly stratified to receive Fe-fortified breakfast cereal ( $16 \mathrm{mg}$ Fe as ferrous sulfate), milk and either two gold kiwifruit or one banana (164 mg $v$. not detectable ascorbic acid; $526 v$. $22.90 \mu \mathrm{g}$ lutein and zeaxanthin, respectively) at breakfast every day for 16 weeks. Biomarkers of Fe status and dietary intake were assessed at baseline and end in the final sample ( $n$ 69). Median serum ferritin increased significantly in the kiwifruit group ( $n$ 33) compared with the banana group ( $n$ 36), with $10 \cdot 0$ (25th, 75th percentiles 3.0, 17.5) v. $1 \cdot 0$ (25th, 75th percentiles $-2 \cdot 8,6 \cdot 5) \mu \mathrm{g} / 1(P<0 \cdot 001)$. Median soluble transferrin receptor concentrations decreased significantly in the kiwifruit group compared with the banana group, with -0.5 (25th, 75 th percentiles $-0 \cdot 7,-0 \cdot 1) v \cdot 0 \cdot 0(25 \mathrm{th}, 75$ th percentiles $-0.3,0 \cdot 4) \mathrm{mg} / \mathrm{l}(P=0 \cdot 001)$. Consumption of an Fe-fortified breakfast cereal with kiwifruit compared with banana improved Fe status. Addition of an ascorbic acid-, lutein- and zeaxanthin-rich fruit to a breakfast cereal fortified with ferrous sulfate is a feasible approach to improve Fe status in women with low Fe stores.

\section{Key words: Iron status: Ferritin: Kiwifruit}

Fe deficiency is the most common nutritional deficiency worldwide and premenopausal women are at particular risk $^{(1)}$. Despite the ease of diagnosis and availability of supplements in countries such as New Zealand, Fe deficiency remains prevalent ${ }^{(2)}$.

Mild Fe deficiency can be treated effectively through dietary intervention ${ }^{(3)}$, including the use of Fe-fortified foods $^{(4)}$ or improving the bioavailability of $\mathrm{Fe}$ within meals ${ }^{(5)}$. It is well known that both synthetic and dietary ascorbic acid enhance $\mathrm{Fe}$ absorption when added to meals ${ }^{(6,7)}$. The effect of carotenoids and vitamin $\mathrm{A}$ on $\mathrm{Fe}$ absorption is controversial. Carotenoids such as lutein and zeaxanthin (which lack provitamin A activity) have been shown to enhance Fe absorption when added to a wheat-based breakfast ${ }^{(8)}$, whereas the addition of vitamin A to maize bread did not improve Fe absorption ${ }^{(9)}$. It is unclear whether enhanced absorption of Fe by ascorbic acid or carotenoids observed in single-meal studies leads to an improved Fe status over time. Previous studies investigating the effect of consuming synthetic or dietary ascorbic acid with meals over a period of several weeks have shown little or no effect on Fe stores due to various reasons. Ascorbic acid enhances $\mathrm{Fe}$ absorption from a single meal containing $\mathrm{Fe}$, but it appears to be less effective on Fe absorption from complete diets ${ }^{(10)}$. Dietary enhancers or inhibitors have less pronounced effects when Fe absorption is measured over several meals or days of intake, compared with measurement in single meals controlled by researchers ${ }^{(11)}$.

Furthermore, studies investigating the effects of ascorbic acid on Fe status had major limitations, including small subject numbers ${ }^{(12-15)}$, short duration of intervention $^{(13-15)}$, subjects not clinically $\mathrm{Fe}$ deficient $^{(12,15)}$ and lack of suitable control groups ${ }^{(12)}$. A well-designed study by Garcia et al. $^{(16)}$ found that the addition of $25 \mathrm{mg}$ ascorbic acid as lime juice to two meals per $\mathrm{d}$ for 8 months did not improve Fe status in eighteen Fe-deficient Mexican women compared with a control group 
consuming a lime-flavoured beverage with no ascorbic $\operatorname{acid}^{(16)}$. This was despite the lime juice having previously been shown by the same research group to increase $\mathrm{Fe}$ absorption when added to meals ${ }^{(6)}$. In addition, it seems likely that when subjects began the studies with low $\mathrm{Hb}$ levels, absorbed $\mathrm{Fe}$ was preferentially used for $\mathrm{Hb}$ synthesis before Fe stores (as indicated by serum ferritin levels) are increased and many of the studies were not continued long enough for this to be observed ${ }^{(13-15)}$

Few of these studies have reported on the Fe content of the meals to which ascorbic acid was added ${ }^{(12)}$ or have only reported total daily $\mathrm{Fe}$ intake $\mathrm{e}^{(13,14,16)}$. In one study that did report the Fe content of meals, only $2 \cdot 24 \mathrm{mg}$ dietary $\mathrm{Fe}$ was consumed at each meal ${ }^{(15)}$. Ascorbic acid may be more likely to improve Fe status if consumed with meals containing substantial amounts of fortificant $\mathrm{Fe}^{(16)}$, especially as ferrous sulfate ${ }^{(17)}$.

It is hypothesised that Fe absorption from a breakfast cereal fortified with a substantial amount of Fe as ferrous sulfate will be enhanced if consumed with kiwifruit - a rich source of ascorbic acid, lutein and zeaxanthin - and may consequently improve Fe status. The present study aimed to investigate whether women's Fe status could be improved by consuming an Fe-fortified breakfast cereal and milk with gold kiwifruit compared with consuming the same breakfast with banana (low in ascorbic acid, lutein and zeaxanthin), each day for 16 weeks.

\section{Experimental methods}

The study protocol is described in detail in a publication by Beck et al. ${ }^{(18)}$. The present study was conducted according to the guidelines laid down in the Declaration of Helsinki and all procedures involving human subjects were approved by the Massey University Human Ethics Committee: (Southern A), reference no. 08/20. Written informed consent was obtained from all subjects. The trial was registered with the Australian New Zealand Clinical Trials Registry (no. ACTRN12608000360314).

\section{Subjects and location}

The research was conducted in Auckland, New Zealand. The sample size (forty-two subjects per group) was calculated with the assumption of a possible clinically important difference in serum ferritin of $2.5 \mu \mathrm{g} / 1$ at $80 \%$ power and $5 \%$ significance (two-sided test). Power calculations were based on a standard deviation for serum ferritin calculated from a group of Fe-deficient women measured in our laboratory (K Beck and J Coad, unpublished results).

A total of 623 women were screened using a range of recruitment methods. Of these, eighty-nine non-anaemic women aged 18-44 years with low Fe stores (defined as a serum ferritin $\leq 25 \mu \mathrm{g} / 1$ and $\mathrm{Hb} \geq 115 \mathrm{~g} / \mathrm{l}$ ) and complying with the exclusion criteria were invited to take part. The cut-off value for serum ferritin $(\leq 25 \mu \mathrm{g} / \mathrm{l})$ is based on the inverse relationship between serum ferritin and Fe absorption ${ }^{(19)}$. When serum ferritin concentrations are greater than $25 \mu \mathrm{g} / 1$ there are only small differences in Fe absorption from foods of varying Fe bioavailability ${ }^{(20)}$.

Exclusion criteria included pregnancy, breast-feeding or any known health problems likely to influence Fe status including inflammatory bowel disease, coeliac disease, history of gastric ulcers, erythrocyte disorders, menorrhagia, haemorrhoids, haematuria or malaria. Women who reported any allergies or intolerances to any components of the breakfast meal were excluded. Subjects had to be prepared not to donate blood or consume Fe, vitamin $\mathrm{C}$ or Ca supplements (or supplements containing these nutrients) for the duration of the study. Women who regularly consumed Fe supplements within the 3-month period before commencement of the study were also excluded.

\section{Study design and procedures}

The study was a 16-week, randomised controlled intervention trial. At baseline, subjects were randomised to either the kiwifruit group ( $n$ 44) or the banana group ( $n$ 45) using stratified randomisation based on serum ferritin concentration and age. Subjects visited the human nutrition research unit at Massey University (Auckland, New Zealand) at baseline and after the 16-week intervention trial for blood samples, anthropometric measurements, questionnaires (demographic, health, blood loss), and dietary assessment.

A fasted venepuncture blood sample was taken for determination of $\mathrm{Hb}$, serum ferritin, soluble transferrin receptor, C-reactive protein, carotenoids and plasma ascorbic acid. Details of blood sample collection and processing procedures and analytical methods are described in Beck et $a{ }^{(18)}$. Samples collected at baseline and end of the study for each subject were analysed in the same assay run to eliminate inter-assay variability.

Height and weight were measured in duplicate at baseline and end by a trained researcher using the International Society for the Advancement of Kinanthropometry protocols ${ }^{(21)}$. Quetelet's BMI was calculated from height and weight.

Subjects completed a face-to-face interview with a researcher at baseline including demographic questions (for example, age, number of children), lifestyle questions (for example, smoking) and a medical history (for example, illness, medication, and supplement use in the past year).

Blood loss is known to affect Fe status ${ }^{(2)}$. Subjects completed a previously validated blood loss questionnaire ${ }^{(22)}$ at baseline and end regarding menstruation, blood donation and nose bleeds. The questionnaire was updated to include details on sanitary items (brand and absorbency) and was completed online.

\section{Dietary intervention and adherence}

Both groups consumed standard portions of an Fe-fortified breakfast cereal and milk every day as breakfast for 
16 weeks. The kiwifruit and banana groups, respectively, consumed two ZESPRI ${ }^{\circledR}$ GOLD (Actinidia chinensis var Hort16A) kiwifruit or one banana with their breakfasts. Subjects were asked to maintain their normal daily routine, including eating patterns (apart from the breakfast), physical activity, alcohol consumption and smoking habits, for the duration of the study.

Each breakfast consisted of pre-packaged individual portions of $64.4 \mathrm{~g}$ breakfast cereal, $150 \mathrm{ml} \mathrm{milk} \mathrm{(Pams}{ }^{\circledR}$ Long Life Slim low-fat $0 \cdot 1 \%$ ultra heat treated milk; Pams, Auckland, New Zealand) and either two ZESPRI ${ }^{\circledR}$ GOLD kiwifruit (171 g; ZESPRI ${ }^{\circledR}$ International Ltd, Mount Maunganui, New Zealand) or a banana (104g; MG Marketing, Auckland, New Zealand). The wheat flake cereal with dried apricot pieces was developed by food technologists at Hubbard Foods Ltd (Mangere, Auckland, New Zealand). Ferrous sulfate AAS $^{\circledR}$ (Zenica BioPlus Pty Ltd, Melbourne, Vic, Australia) was added to provide $16 \mathrm{mg} \mathrm{Fe}(1.92 \mathrm{mg}$ natural Fe, $14.1 \mathrm{mg}$ ferrous sulfate) per serve. Fruit of a consistent size was delivered to subjects each week for the bananas (in various stages of ripeness) and every fortnight for the kiwifruit (stored at $1^{\circ} \mathrm{C}$ until delivery). Details of sampling and analytical methods for the breakfast meals are described in Beck et al. ${ }^{(18)}$. The breakfast meals and intervention food items were analysed and their nutritional composition is reported in Table 1 . The ascorbic acid content of the two gold kiwifruit decreased from $182 \mathrm{mg}$ (first 6 weeks of the study) to $144 \mathrm{mg}$ (final 6 weeks) during storage of the fruit.

Subjects were asked to eat the fruit with, immediately before or immediately after consuming the breakfast cereal and not to consume any other food or fluids (apart from plain tap water) with the breakfast meal or $1 \mathrm{~h}$ before or after consuming the breakfast meal.

All subjects completed a daily compliance diary, including whether they ate breakfast, the time of consumption, any food not consumed, or any other food eaten with or consumed within $1 \mathrm{~h}$ either side of the breakfast. As part of this diary, subjects reported in a weekly section on illnesses, medication use, symptoms experienced from the intervention, changes to their normal daily routine, supplement use, and any practical problems with eating the breakfast. Subjects were emailed twice and telephoned at weeks 2, 4, 8 and 12 of the study to provide support, maintain subject motivation, and answer any questions regarding the intervention.

\section{Dietary assessment}

A 144-item FFQ was developed for the present study, grouping foods known to affect $\mathrm{Fe}$ absorption according to their similarities, frequency of consumption and nutrient content, based on average portion sizes. Subjects completed the FFQ at baseline and end. The FFQ was used to assess their food intake over the past month and to assess any changes in intake within and between groups over the course of the study. Responses were converted into serving sizes per week for each subject and then combined into the following food groupings: gold kiwifruit; bananas; breakfast cereal; fruit (medium and high ascorbic acid content); all other fruit; vegetables (medium and high ascorbic acid content); all other vegetables; grains, breads, cakes and biscuits; red meat and offal; white meat; fish and seafood; eggs; nuts and seeds; tofu and soya products; legumes; dairy products; coffee, black and herbal teas; fruit juice and alcohol.

\section{Statistical analysis}

Statistical analysis was performed using SPSS for Windows version 16 (SPSS Inc., Chicago, IL, USA). Subjects with a C-reactive protein concentration greater than $10 \mathrm{mg} / \mathrm{l}$ at either baseline or end were excluded from the analysis, as a high C-reactive protein is associated with infection and elevated serum ferritin concentrations which can lead to overestimation of body Fe stores $^{(23)}$. Descriptive

Table 1. Analysis of nutrient content of the intervention meals and fruit

\begin{tabular}{|c|c|c|c|c|c|}
\hline & $\begin{array}{l}\text { Fe-fortified cereal } \\
\begin{array}{c}(64.4 \mathrm{~g})+\text { milk } \\
(150 \mathrm{ml})\end{array}\end{array}$ & $\begin{array}{c}\text { Fe-fortified cereal, } \\
\text { milk + kiwifruit } \\
(171 \mathrm{~g})\end{array}$ & $\begin{array}{l}\text { Fe-fortified cereal, } \\
\text { milk + banana } \\
(104 \mathrm{~g})\end{array}$ & $\begin{array}{c}\text { Kiwifruit } \\
(171 \mathrm{~g})\end{array}$ & $\begin{array}{c}\text { Banana } \\
\text { (104 g) }\end{array}$ \\
\hline Gross energy (kJ) & $1598 \cdot 0$ & $2068 \cdot 0$ & $2004 \cdot 0$ & $470 \cdot 0$ & $406 \cdot 0$ \\
\hline Protein (g) & $16 \cdot 2$ & $17 \cdot 7$ & $17 \cdot 3$ & 1.5 & $1 \cdot 1$ \\
\hline Total fat $(\mathrm{g})$ & $2 \cdot 2$ & $2 \cdot 7$ & $2 \cdot 3$ & 0.5 & 0.1 \\
\hline Total carbohydrate $(\mathrm{g})$ & $60 \cdot 8$ & $79 \cdot 1$ & $80 \cdot 1$ & $18 \cdot 3$ & $19 \cdot 3$ \\
\hline Ascorbic acid (mg) & 1.4 & $164 \cdot 0$ & 1.4 & $163 \cdot 0$ & ND \\
\hline $\mathrm{Fe}(\mathrm{mg})$ & $16 \cdot 2$ & $16 \cdot 6$ & $16 \cdot 4$ & 0.4 & $0 \cdot 2$ \\
\hline Dietary fibre (g) & $4 \cdot 3$ & 6.5 & $5 \cdot 8$ & $2 \cdot 1$ & 1.5 \\
\hline $\mathrm{Ca}(\mathrm{mg})$ & $391 \cdot 0$ & $426 \cdot 0$ & $392 \cdot 0$ & $35 \cdot 0$ & $1 \cdot 0$ \\
\hline$P(\mathrm{mg})$ & $437 \cdot 0$ & $488 \cdot 0$ & $462 \cdot 0$ & $51 \cdot 0$ & $25 \cdot 0$ \\
\hline Vitamin A (as retinol) $(\mu \mathrm{g})$ & ND & ND & ND & ND & ND \\
\hline Lutein and zeaxanthin $(\mu \mathrm{g})$ & ND & $194 \cdot 9$ & 22.9 & 194.9 & 22.9 \\
\hline Citric acid (mg) & $279 \cdot 0$ & $2328 \cdot 0$ & $591 \cdot 0$ & $2049 \cdot 0$ & $312 \cdot 0$ \\
\hline Polyphenols (mg) & $44 \cdot 6$ & $79 \cdot 6$ & $55 \cdot 6$ & $35 \cdot 0$ & $11 \cdot 0$ \\
\hline Phytic acid (mg) & $238 \cdot 0$ & $272 \cdot 0$ & $238 \cdot 0$ & $34 \cdot 0$ & ND \\
\hline
\end{tabular}

ND, not detectable. 
statistics were used to describe the study population using mean values and standard deviations, median values with 25 th and 75 th percentiles, or frequency summary statistics. Normality of distribution was evaluated using the Kolmogorov-Smirnov test. Non-normally distributed variables were transformed into approximately normal distributions by logarithmic transformations and again tested for normality.

Comparisons between groups at baseline were made using the independent $t$ test for parametric data, the Mann-Whitney test for non-parametric data, and the $\chi^{2}$ test for frequencies. Subjects who did not complete the study or who were excluded from the analysis were compared with subjects who completed the study using these same statistical tests. The main analysis was the comparison of the change in serum ferritin from baseline to 16 weeks between the kiwifruit and the banana groups. Changes in $\mathrm{Hb}$, serum soluble transferrin receptor, serum soluble transferrin receptor:serum ferritin ratio, plasma ascorbic acid, serum lutein and zeaxanthin, and dietary intake between groups were also investigated. Independent $t$ tests were used for parametric data and the Mann-Whitney test for non-parametric data. Comparisons were made within the kiwifruit and banana groups between baseline and endpoint measures using the dependent $t$ test for parametric data and the Wilcoxon signedrank test for non-parametric data. Serum ferritin, soluble transferrin receptor, soluble transferrin receptor:serum ferritin ratio and ascorbic acid were tested using one-sided tests. Two-sided tests were used for all other variables.

Since BMI levels differed between the two groups at baseline, a two-way ANOVA was used to test for interaction or main effects between BMI and the intervention and its impact on change in serum ferritin. Significance was set at $P<0 \cdot 05$. The percentage of days that each subject consumed the study breakfast meal was calculated from compliance diaries (number of days the study breakfast was consumed/112 (total number of days on the study) $\times 100$ ).

\section{Results}

\section{Subjects}

Of the eighty-nine women with low Fe stores enrolled in the study, sixty-nine (thirty-three women in the kiwifruit group and thirty-six women in the banana group) were included in the final analysis. Of the original participants, eleven withdrew from the study (five from the kiwifruit group and six from the banana group), and a further nine were excluded from the final analysis due to non-compliance, use of supplements, medical conditions or elevated C-reactive protein concentrations. Baseline serum ferritin concentrations were significantly higher $(P=0.02)$ in women who withdrew or were excluded from the final analysis (median 21.0 (25th, 75th percentiles $16.3,31.8) \mu \mathrm{g} / \mathrm{l})$ compared with women who completed the study (median 17.0 (25th, 75th percentiles $10 \cdot 0,21 \cdot 0) \mu \mathrm{g} / \mathrm{l})$. Women who did not complete the study or who were excluded from the final analysis did not differ with regard to other baseline characteristics.

\section{Adherence}

Subjects completed $112 \mathrm{~d}$ on the study. Compliance diaries were available for all women (100\%) in the kiwifruit group ( $n$ 33) and for thirty-four women (94.4\%) in the banana group. The mean compliance rate in the kiwifruit group was 97 (SD 5.12) \% compared with 98 (SD 3.68)\% in the banana group. Of the women, $91 \%$ of women in the kiwifruit group and $97 \%$ of women in the banana group reported a compliance rate of greater than $90 \%$.

\section{Baseline characteristics}

The baseline characteristics of the women are shown in Tables 2 and 3. At baseline there were no significant differences between the groups for any of the variables or factors affecting Fe status such as having children, menstrual blood loss or blood donation. BMI was significantly

Table 2. Baseline characteristics of study subjects

(Medians and 25th and 75th percentiles, mean values and standard deviations or frequency)

\begin{tabular}{|c|c|c|c|c|c|}
\hline & \multicolumn{2}{|c|}{ Kiwifruit group ( $n$ 33) } & \multicolumn{2}{|c|}{ Banana group ( $n$ 36) } & \multirow[b]{2}{*}{$P^{\star}$} \\
\hline & Median & 25th, 75th percentiles & Median & 25th, 75th percentiles & \\
\hline Age (years) & $31 \cdot 0$ & $24 \cdot 0,39 \cdot 5$ & $35 \cdot 0$ & $22 \cdot 5,41 \cdot 0$ & 0.41 \\
\hline Weight (kg) & & & & & 0.16 \\
\hline Mean & & $62 \cdot 4$ & & $66 \cdot 1$ & \\
\hline SD & & $7 \cdot 2$ & & $13 \cdot 8$ & \\
\hline Height (cm) & & & & & $0 \cdot 10$ \\
\hline Mean & & $166 \cdot 3$ & & $163 \cdot 7$ & \\
\hline SD & & $6 \cdot 1$ & & $6 \cdot 8$ & \\
\hline $\mathrm{BMI}\left(\mathrm{kg} / \mathrm{m}^{2}\right) \dagger$ & $22 \cdot 4$ & $21 \cdot 2,23 \cdot 7$ & $24 \cdot 1$ & $21 \cdot 8,26 \cdot 7$ & 0.02 \\
\hline Menstrual blood loss (BLU) & $46 \cdot 5$ & $22 \cdot 8,57 \cdot 0$ & $47 \cdot 5$ & $28 \cdot 8,66 \cdot 0$ & 0.36 \\
\hline Blood donor in the past year (\%) & & $24 \cdot 2$ & & $19 \cdot 4$ & 0.77 \\
\hline Has children (\%) & & 54.5 & & $61 \cdot 1$ & 0.63 \\
\hline
\end{tabular}

BLU, blood loss units.

* Difference between groups (independent $t$ test, Mann-Whitney test or $\chi^{2}$ test).

$\dagger \mathrm{BMI}$ values are reported as geometric means and $95 \% \mathrm{Cl}$. 
Table 3. Changes from baseline to end measures of iron status, plasma ascorbic acid and serum lutein and zeaxanthin within and between kiwifruit and banana groups

(Medians and 25th and 75th percentiles or mean values and standard deviations)

\begin{tabular}{|c|c|c|c|c|c|}
\hline & \multicolumn{2}{|r|}{ Kiwifruit (n 33) } & \multicolumn{2}{|r|}{ Banana (n 36) } & \multirow[b]{2}{*}{$P^{*}$} \\
\hline & Median & 25th, 75th percentiles & Median & 25th, 75th percentiles & \\
\hline \multicolumn{6}{|c|}{ Serum ferritin† } \\
\hline Baseline & $17 \cdot 0$ & $10 \cdot 5,22 \cdot 0$ & $16 \cdot 5$ & $10 \cdot 0,20 \cdot 8$ & 0.40 \\
\hline End & $25 \cdot 0$ & $20 \cdot 0,32 \cdot 0$ & $17 \cdot 5$ & $12 \cdot 3,22 \cdot 8$ & \\
\hline Change & $10 \cdot 0$ & $3 \cdot 0,17 \cdot 5$ & 1.0 & $-2 \cdot 8,6 \cdot 5$ & $<0.001$ \\
\hline$P \S$ & & $<0.001$ & & 0.09 & \\
\hline \multicolumn{6}{|l|}{$\mathrm{Hb} \|$} \\
\hline Baseline & & & & & 0.78 \\
\hline Mean & & $126 \cdot 0$ & & $125 \cdot 0$ & \\
\hline SD & & $8 \cdot 8$ & & $9 \cdot 0$ & \\
\hline \multicolumn{6}{|l|}{ End } \\
\hline Mean & & $130 \cdot 0$ & & $126 \cdot 0$ & \\
\hline SD & & $7 \cdot 6$ & & $9 \cdot 0$ & \\
\hline Changeł & & & & & 0.14 \\
\hline Mean & & $3 \cdot 8$ & & 1.2 & \\
\hline SD & & $7 \cdot 2$ & & $6 \cdot 9$ & \\
\hline$P \S$ & & 0.005 & & 0.30 & \\
\hline \multicolumn{6}{|c|}{ Soluble transferrin receptorq } \\
\hline Baseline & $3 \cdot 1$ & $2 \cdot 5,3 \cdot 8$ & 3.5 & $2 \cdot 7,4 \cdot 0$ & 0.13 \\
\hline End & $2 \cdot 7$ & $2 \cdot 1,3 \cdot 0$ & $3 \cdot 6$ & $2 \cdot 6,4 \cdot 2$ & \\
\hline Changeł & -0.5 & $-0.7,-0.1$ & $0 \cdot 0$ & $-0.3,0.4$ & 0.001 \\
\hline$P \S$ & & $<0.001$ & & 0.32 & \\
\hline \multicolumn{6}{|c|}{ Soluble transferrin receptor:serum ferritin ratio** } \\
\hline Baseline & 188.0 & $116 \cdot 0,288 \cdot 0$ & $200 \cdot 0$ & $157 \cdot 0,333 \cdot 0$ & 0.32 \\
\hline End & $116 \cdot 0$ & $77 \cdot 2,150 \cdot 0$ & $186 \cdot 0$ & $132 \cdot 0,346 \cdot 0$ & \\
\hline Change & -89.5 & $-183 \cdot 0,-38 \cdot 4$ & -0.2 & $-124 \cdot 0,65 \cdot 9$ & 0.008 \\
\hline$P \S$ & & $<0.001$ & & 0.20 & \\
\hline \multicolumn{6}{|c|}{ Plasma ascorbic acid†† } \\
\hline Baseline & $70 \cdot 0$ & $52 \cdot 0,79 \cdot 5$ & $65 \cdot 0$ & $56 \cdot 3,72 \cdot 8$ & 0.20 \\
\hline End & $76 \cdot 0$ & $69 \cdot 0,83 \cdot 0$ & $66 \cdot 0$ & $56 \cdot 3,72 \cdot 0$ & \\
\hline Change & $7 \cdot 0$ & $-3 \cdot 5,19 \cdot 0$ & $3 \cdot 0$ & $-4 \cdot 8,10 \cdot 8$ & 0.07 \\
\hline$P \S$ & & 0.002 & & 0.15 & \\
\hline \multicolumn{6}{|c|}{ Serum lutein and zeaxanthin } \\
\hline Baseline & $413 \cdot 0$ & $311 \cdot 0,540 \cdot 0$ & $378 \cdot 0$ & $269 \cdot 0,506 \cdot 0$ & 0.27 \\
\hline End & $497 \cdot 0$ & $356 \cdot 0,658 \cdot 0$ & 438.0 & $288 \cdot 0,496 \cdot 0$ & \\
\hline Change & $64 \cdot 0$ & $11 \cdot 5,132 \cdot 0$ & $12 \cdot 0$ & $-59 \cdot 0,95 \cdot 0$ & 0.03 \\
\hline$P \S$ & & 0.002 & & 0.33 & \\
\hline
\end{tabular}

* Difference between groups (independent $t$ test or Mann-Whitney test).

† Normal reference range for serum ferritin: $20-160 \mu \mathrm{g} /$; Diagnostic MedLab, Auckland, New Zealand.

$\ddagger$ Change: end value - baseline value.

$\S$ Difference between baseline and end (dependent $t$ test or Wilcoxon signed-rank test).

|l Normal reference range for $\mathrm{Hb}: 115-160 \mathrm{~g} / \mathrm{l}$; Diagnostic MedLab.

ๆ Normal reference range for soluble transferrin receptor: $2 \cdot 2-4.5 \mathrm{mg} / \mathrm{l}$; LabPlus, Auckland, New Zealand.

${ }_{\star *}$ Normal reference range for soluble transferrin receptor:serum ferritin ratio: $<100^{(44)}$

†† Normal reference range for plasma ascorbic acid: $20-80 \mu \mathrm{mol} / \mathrm{l}$; LabPlus.

lower in the kiwifruit group compared with the banana group at baseline $(P=0.02)$, although this difference was very small. These differences in BMI at the beginning of the study had no effect on the change in serum ferritin concentrations. BMI and menstrual blood loss did not change within or between groups over the course of the study.

\section{Biochemical assessment}

The changes in Fe status, plasma ascorbic acid and serum lutein and zeaxanthin from baseline to end are presented in Table 3. Serum ferritin concentrations increased significantly in the kiwifruit group from baseline to end $(P<0.001)$, but there was no effect in the banana group $(P=0.09)$. The difference in the change between the two groups was also highly significant $(P<0 \cdot 001)$. $\mathrm{Hb}$ concentrations increased significantly in the kiwifruit group $(P=0.005)$, but not within the banana group $(P=0 \cdot 30)$, and the change between groups was not significantly different $(P=0 \cdot 14)$. Soluble transferrin receptor concentrations decreased significantly in the kiwifruit group ( $P<0.001)$, but not in the banana group $(P=0.32)$, and the difference in change between the groups was statistically significant $(P=0 \cdot 001)$. The soluble transferrin receptor:serum ferritin ratio decreased significantly in the kiwifruit group $(P<0 \cdot 001)$, with no change in the banana group $(P=0 \cdot 20)$. The difference in change between the groups was statistically significant $(P=0 \cdot 008)$.

Plasma ascorbic acid concentrations increased significantly $(P=0.002)$ in the kiwifruit group from baseline to 
end, but there was no change in the banana group $(P=0 \cdot 15)$. The difference in the changes between the two groups was almost significant $(P=0.07)$. Serum lutein and zeaxanthin increased significantly within the kiwifruit group ( $P=0.002)$, but not in the banana group $(P=0.33)$, and the difference in the change between groups was significant $(P=0 \cdot 03)$

\section{Dietary assessment}

There were no significant differences in dietary intake between the kiwifruit and banana groups at baseline. As expected, subjects in the kiwifruit and banana groups significantly increased their intake of gold kiwifruit $(P<0 \cdot 001)$ and bananas $(P=0.02)$, respectively, from baseline to end. The intake of medium to high ascorbic acid-containing fruits decreased significantly over the course of the study in the kiwifruit group (median -2.9 (25th, 75th percentiles $-5,0 \cdot 1)$ servings/week) compared with the banana group (median $-0.8(25$ th, 75 th percentiles $-2.5,0.7)$ servings/ week) $(P=0 \cdot 02)$. Red meat and offal intake decreased significantly in both the kiwifruit $(P=0.02)$ and banana $(P=0 \cdot 01)$ groups although the decreases were small (median $-0 \cdot 1$ (25th, 75th percentiles $-2 \cdot 0,0 \cdot 2)$ and median -0.4 (25th, 75th percentiles $-2 \cdot 1,0 \cdot 0)$ servings per week, respectively). The difference in change between groups was not significant $(P=0.63)$. Similarly, the intake of grains, breads, cakes and biscuits decreased significantly in both the kiwifruit $(P<0.001)$ and banana $(P=0.05)$ groups, although the difference in change between the groups was not significant $(P=0.61)$. In this instance, however, the portions consumed decreased in both groups with about four to six portions showing the possible replacement due to the consistent daily intake of breakfast cereal.

\section{Side effects}

The majority ( $n 40 ; 58 \%$ ) of the women who completed the study (nineteen from the kiwifruit group and twentyone from the banana group) reported no side effects of eating the breakfast meal. Positive effects such as regular bowel movements, better skin, not feeling as hungry and a feeling of more energy were reported by fifteen $(21.7 \%)$ of the women (seven from the kiwifruit group and eight from the banana group). In total, $26 \cdot 1 \%$ ( $n$ 18) of the women reported a negative side effect associated with the breakfast (seven from the kiwifruit group and eleven from the banana group). Most of the reported negative effects related to initial nausea, constipation or diarrhoea which subsided during the course of the study.

\section{Discussion}

As far as we are aware, this is the first randomised controlled intervention trial to investigate the effect of an
Fe-fortified breakfast cereal plus an ascorbic acid-, luteinand zeaxanthin-rich kiwifruit compared with banana (low ascorbic acid, lutein and zeaxanthin) on $\mathrm{Fe}$ status in healthy women with low Fe stores. The results showed an improvement in Fe status (increased serum ferritin; decreased serum soluble transferrin receptor and soluble transferrin receptor:ferritin ratio) following the 16-week intervention.

Ascorbic acid is the most widely used enhancer of fortified $\mathrm{Fe}^{(17)}$ and increases $\mathrm{Fe}$ absorption in a dosedependent manner ${ }^{(7)}$. Ascorbic acid enhances Fe absorption by reducing ferric Fe to ferrous Fe, for transport by divalent metal transport protein 1 into the intestinal mucosal cell. Ascorbic acid also forms a soluble chelate with Fe, preventing it being precipitated as insoluble compounds, such as ferric hydroxide or ferric phosphate, or binding to inhibitory ligands such as phytate ${ }^{(24)}$. An ascorbic acid:Fe molar ratio of $4: 1$ is needed to increase Fe absorption from fortified foods high in phytic acid(17). The ascorbic acid:Fe molar ratio of the kiwifruit breakfast meal provided in the present study was 3·7:1. Ascorbic acid may be unstable during food processing, storage and cooking, therefore consuming natural sources of ascorbic acid such as fruits and vegetables with Fe-fortified foods is recommended ${ }^{(25)}$. Hallberg et al. $^{(26)}$ suggested that $50 \mathrm{mg}$ ascorbic acid is needed to enhance Fe absorption in a meal, although this is likely to depend on the components of the meal and other studies have shown smaller amounts of ascorbic acid to be successful in enhancing Fe absorption ${ }^{(6)}$. The kiwifruit supplied in the present study provided $163 \mathrm{mg}$ ascorbic acid.

Although it is well established that ascorbic acid increases Fe absorption, previous studies have not shown an improvement in Fe status over time with the consumption of ascorbic acid. These studies had several limitations (sample size, short duration, Fe-replete subjects, no control groups, ascorbic acid not specifically used with absorbable $\mathrm{Fe})^{(12-15)}$. These limitations were all addressed within the present study as follows: a sufficient sample size to detect the expected small changes in biomarkers of $\mathrm{Fe}$ status; a 16-week intervention allowing sufficient time for erythrocyte turnover and improvement of Fe stores; a control group was used; only subjects with low Fe stores were included; the ascorbic acid-rich fruit was added to a meal containing a significant amount of $\mathrm{Fe}(16 \mathrm{mg} \mathrm{Fe}$ as ferrous sulfate).

Serum ferritin is routinely used and is a wellstandardised and sensitive measure of Fe stores ${ }^{(27)}$. Soluble transferrin receptor is a stable and highly sensitive indicator of functional or tissue $\mathrm{Fe}$, not subject to biological variation or affected by inflammation ${ }^{(27,28)}$. Serum ferritin is reduced during the depletion of Fe stores, while soluble transferrin receptor is not affected. During functional Fe deficiency, however, soluble transferrin receptor increases, while serum ferritin remains unchanged. Therefore, the decrease in the ratio of soluble transferrin saturation and serum 
ferritin is a more specific and sensitive indicator of improved Fe status than either measure alone ${ }^{(29)}$. This ratio decreased significantly in the kiwifruit group compared with the banana group. The women who consumed kiwifruit had improved functional $\mathrm{Fe}$ and stored $\mathrm{Fe}$ at the end of the study, whereas women who consumed bananas, despite receiving an equivalent amount of $\mathrm{Fe}$, did not improve their Fe status.

The plasma ascorbic acid status of the women in the kiwifruit group showed a significant increase, from 70 to $76 \mu \mathrm{mol} / \mathrm{l}$, over the course of the intervention compared with no change in the banana group. Plasma ascorbic acid concentrations have been shown to increase linearly with dietary intake (up to $60-70 \mathrm{mg} / \mathrm{d}$ ), but only up to a plateau of $75 \mu \mathrm{mol} / \mathrm{l}^{(28)}$. Therefore, further increases in plasma ascorbic acid were not expected to be seen with the large quantities of ascorbic acid provided by the kiwifruit. Although the intake of fruits with medium and high vitamin $\mathrm{C}$ content decreased in the kiwifruit group compared with the banana group, the Fe status in the kiwifruit group still improved, probably indicating that it is more important to consider whether ascorbic acid is added to a meal containing $\mathrm{Fe}$ than to focus on the total daily intake of ascorbic acid.

Lutein and zeaxanthin have been shown to improve Fe absorption in human subjects ${ }^{(8)}$; however, no studies have investigated their effects on Fe status when consumed with meals for an extended period of time. Serum lutein and zeaxanthin concentrations increased significantly in the kiwifruit group compared with the banana group. The improvement seen in Fe status in the kiwifruit group could have been due to the ascorbic acid, carotenoids or a combination of nutritional factors in kiwifruit. The kiwifruit contained over $2000 \mathrm{mg}$ citric acid (more than six times the citric acid content of the banana) which may also have contributed to the increased Fe status seen in the kiwifruit group. The effect of citric acid has been shown to be additive to the effect of ascorbic acid on Fe absorption ${ }^{(30)}$.

The level of Fe fortification within the present study was set at $16 \mathrm{mg}$ per serve, providing more than $80 \%$ of the current recommended daily intake $(18 \mathrm{mg})$ for $\mathrm{Fe}^{(31)}$. Zimmermann et al. ${ }^{(32)}$ found that adding $12 \mathrm{mg}$ Fe per $\mathrm{d}$ as snack foods increased Fe status in women with low Fe stores $^{(32)}$. Despite this, the banana group did not show an improvement in Fe status. Fe fortification at $16 \mathrm{mg}$ Fe as ferrous sulfate per serve alone may not have been adequate to overcome the inhibitory effects on Fe absorption of the $\mathrm{Ca}$ or phytic acid contained in the breakfast meals ${ }^{(33,34)}$. While $\mathrm{Ca}$ inhibits $\mathrm{Fe}$ absorption $^{(34)}$, supplemental Ca consumed with meals ${ }^{(35)}$ or Ca supplementation as high has $1200 \mathrm{mg} / \mathrm{d}$ did not appear to affect Fe status in Fe-replete women over time ${ }^{(36)}$. However, further research is needed to see whether the Fe stores of Fe-depleted women (such as those in the present study) are affected by high $\mathrm{Ca}$ intakes ${ }^{(36)}$. Phytic acid has a strong inhibitory effect on Fe absorption ${ }^{(37)}$. Sodium phytate decreased $\mathrm{Fe}$ absorption in a dose-dependent manner when added to a wheat roll, while the addition of 50 and $100 \mathrm{mg}$ ascorbic acid significantly counteracted the effect of sodium phytate ${ }^{(37)}$. Hurrell et al. ${ }^{(38)}$ suggested that decreasing the phytic acid content of a meal from 220 to $110 \mathrm{mg}$ would have little effect on improving $\mathrm{Fe}$ absorption, but by decreasing the phytic acid content to $<10 \mathrm{mg} / \mathrm{meal}$, Fe absorption would increase substantially. The phytic acid content of the banana meal was $238 \mathrm{mg}$ and could have therefore had a negative effect on Fe absorption if not counteracted by ascorbic acid. Very few studies have investigated the long-term effect of phytic acid on Fe status. Kristensen et al. ${ }^{(39)}$ found that serum ferritin concentrations decreased significantly in Fe-replete women given fibre-rich bread containing phytate over a 4-month period. In another study, soya protein containing native phytate significantly reduced serum ferritin levels in subjects after 6 weeks $^{(40)}$. It is likely that the phytic acid contained in the breakfast cereal may have inhibited Fe absorption, which the kiwifruit but not the banana was able to overcome. It is unlikely that the banana itself inhibited Fe absorption. The banana contained similar or lower levels of dietary fibre, Ca, polyphenols and phytic acid (substances all known to inhibit Fe absorption) than the kiwifruit. Thus, adding $16 \mathrm{mg}$ Fe as ferrous sulfate to a breakfast cereal eaten with milk was ineffective at improving Fe status unless eaten with an ascorbic acid-, lutein- and zeaxanthin-rich fruit.

Breakfast cereal was chosen as a suitable vehicle to fortify with $\mathrm{Fe}^{(41)}$, and as a food item that is acceptable to consume with fruit. A food-based approach represents a desirable and potentially sustainable method of addressing the issue of Fe deficiency ${ }^{(42)}$, which may also confer other nutritional benefits compared with simple nutrient supplementation. Self-reported compliance to the breakfast protocol was high, probably because the breakfast was feasible for women to incorporate into their daily lives and due to the high levels of support received from the researchers over the study. They simply replaced one breakfast item for another, which meant little interference with the rest of the family. Few women reported any side effects due to the breakfast meal. Negative side effects included initial nausea which could be related to the size of the breakfast being consumed, constipation or diarrhoea possibly due to the fortificant which subsided during the course of the study as tolerance increased. Several positive effects were also noted including regular bowel movements due to the cereal and fruit combination, healthier skin, reduced hunger and higher energy levels which may be related to healthier eating habits. An alternative to dietary intervention is Fe supplementation, but this may not be feasible due to poor compliance, often attributed to the side effects experienced ${ }^{(43)}$. Increasing the intake of meat, fish and poultry is often recommended to improve Fe status. However, a study in New Zealand found that 
women were only able to increase their intake of flesh food by $31 \mathrm{~g} / \mathrm{d}$ (equivalent to one-third of a meat serving per d), despite receiving intensive dietary counselling to improve the Fe bioavailability in their diet. However, these women increased their intake of ascorbic acid by $136 \mathrm{mg} / \mathrm{d}^{(3)}$. Therefore, the inclusion of a combination of fruit high in ascorbic acid, lutein and zeaxanthin and an Fe-fortified breakfast cereal may be far more achievable for these women to improve their Fe status compared with other approaches. The optimal level of Fe fortification in various foods, and the impact of other fruit or foods high in ascorbic acid, lutein and zeaxanthin consumed with Fe-fortified foods on Fe status should be investigated, also taking into account consumer acceptability and accessibility.

In conclusion, the consumption of an ascorbic acid-, lutein- and zeaxanthin-rich fruit (kiwifruit) compared with a banana (low ascorbic acid, lutein and zeaxanthin) with an Fe-fortified breakfast cereal meal improved Fe status in women with low Fe stores. The addition of an ascorbic acid-, lutein- and zeaxanthin-rich fruit to a breakfast cereal fortified with ferrous sulfate may be a more feasible approach of addressing Fe deficiency in young women compared with other approaches.

\section{Acknowledgements}

We would like to thank all the women who participated in the present study. We gratefully acknowledge Lynley Drummond for assistance with the production and sourcing of the breakfast cereal; Pam von Hurst and Carlos Miranda for their assistance in processing the blood; Dmitri Roukin for assistance with the website and online questionnaires; Simon Bennett for his phlebotomy skills and Christa Riekert, Solenn Beaunieux, Liza Phillips, Tess Philpott and Olivia Green for their assistance with data collection. The present study was supported by ZESPRI $^{\circledR}$ International Ltd. Additional funding was provided by Massey University Research Fund and the New Horizons for Women Trust Research Award. K. B. was the recipient of the New Zealand Dietetic Association Neige Todhunter Award.

K. B. was the main author of the paper, project leader together with C. C., and involved in all aspects of the study including conceptualising and the design of the research project, the acquisition of data and statistical analysis. C. C. was the project leader together with K. B., and involved in all aspects of the study including conceptualising and the design of the research project, the acquisition of data, revising and approving the manuscript. R. K. was involved in conceptualising and the design of the research project, the acquisition of data, especially dietary intake data and revising and approving the manuscript. J. C. interpreted the results related to Fe status, revising and approving the manuscript. W. S. was involved in conceptualising and the design of the research project, the acquisition of data, overseeing statistical analysis and revising and approving the manuscript.

None of the authors has any conflict of interest.

\section{References}

1. Food and Agriculture Organization and World Health Organization (2002) Iron. In Human Vitamin and Mineral Requirements: Report of a Joint FAO/WHO Expert Consultation, Bangkok, Thailand, pp. 195-221. Rome: FAO.

2. Heath ALM, Skeaff CM, Williams S, et al. (2001) The role of blood loss and diet in the aetiology of mild iron deficiency in premenopausal adult New Zealand women. Public Health Nutr 4, 197-206.

3. Heath ALM, Skeaff CM, O'Brien SM, et al. (2001) Can dietary treatment of non-anemic iron deficiency improve iron status? J Am Coll Nutr 20, 477-484.

4. Hurrell RF, Lynch S, Bothwell T, et al. (2004) Enhancing the absorption of fortification iron: a SUSTAIN Task Force report. Int J Vitam Nutr Res 74, 387-401.

5. Rossander-Hulthen L \& Hallberg L (1996) Dietary factors influencing iron absorption - an overview. In Iron Nutrition in Health and Disease, pp. 105-115 [L Hallberg and N Asp, editors]. London: John Libbey and Company Ltd.

6. Diaz M, Rosado JL, Allen LH, et al. (2003) The efficacy of a local ascorbic acid-rich food in improving iron absorption from Mexican diets: a field study using stable isotopes. Am J Clin Nutr 78, 436-440.

7. Cook JD \& Monsen ER (1977) Vitamin C, the common cold and iron absorption. Am J Clin Nutr 30, 235-241.

8. Garcia-Casal MN (2006) Carotenoids increase iron absorption from cereal-based food in the human. Nutr Res $\mathbf{2 6}$, 340-344.

9. Walczyk T, Davidsson L, Rossander-Hulthen L, et al. (2003) No enhancing effect of vitamin A on iron absorption in humans. Am J Clin Nutr 77, 144-149.

10. Cook JD \& Reddy MB (2001) Effect of ascorbic acid intake on nonheme-iron absorption from a complete diet. Am J Clin Nutr 73, 93-98.

11. Reddy MB, Hurrell RF \& Cook JD (2000) Estimation of nonheme-iron bioavailability from meal composition. Am J Clin Nutr 71, 937-943.

12. Cook JD, Watson SS, Simpson KM, et al. (1984) The effect of high ascorbic acid supplementation on body iron stores. Blood 64, 721-726.

13. Hunt JR, Mullen LM, Lykken GI, et al. (1990) Ascorbic acid: effect on ongoing iron absorption and status in iron-depleted young women. Am J Clin Nutr 51, 649-655.

14. Hunt JR, Gallagher SK \& Johnson LK (1994) Effect of ascorbic acid on apparent iron absorption by women with low iron stores. Am J Clin Nutr 59, 1381-1385.

15. Kandiah J (2002) Impact of tofu or tofu + orange juice on hematological indices of lacto-ovo vegetarian females. Plant Foods Hum Nutr 57, 197-204.

16. Garcia OP, Diaz M, Rosado JL, et al. (2003) Ascorbic acid from lime juice does not improve the iron status of iron-deficient women in rural Mexico. Am J Clin Nutr 78, 267-273.

17. Hurrell RF (2002) Fortification: overcoming technical and practical barriers. J Nutr 132, 806S-812S.

18. Beck K, Conlon C, Kruger R, et al. (2010) The effect of gold kiwifruit consumed with an iron fortified breakfast cereal meal on iron status in women with low iron stores: a 16 week randomised controlled intervention study. BMC Public Health 10, 36. 
19. Taylor P, Martinez-Torres C, Leets I, et al. (1988) Relationships among iron absorption, percent saturation, of plasma transferrin and serum ferritin concentration in humans. J Nutr 118, 1110-1115.

20. Fairweather-Tait SJ (1995) Iron absorption. In Iron: Nutritional and Physiological Significance, pp. 3-12 [British Nutrition Foundation, editor]. London: Chapman and Hall.

21. Marfell-Jones M, Olds T, Stewart A, et al. (2006) International Standards for Anthropometric Assessment. Potchefstroom, South Africa: International Society for the Advancement of Kinanthropometry.

22. Heath AL, Skeaff CM \& Gibson RS (1998) Validation of a questionnaire method for estimating extent of menstrual blood loss in young adult women. I Trace Elem Med Biol 12, 231-235.

23. Hulthen L, Lindstedt G, Lundberg P-A, et al. (1998) Effect of mild infection on serum ferritin concentration - clinical and epidemiological implications. Eur J Clin Nutr 52, 376-379.

24. Allen LH \& Ahluwalia N (1997) Improving iron status through diet: the application of knowledge concerning dietary iron bioavailability in human populations. MOST: The USAID Micronutrient Program. http://www.mostproject. org/Archives.htm\#IronArchives (accessed May 2010).

25. Teucher B, Olivares M \& Cori H (editors) (2003) Enhancers of Iron Absorption: Ascorbic Acid and Other Organic Acids. Sustain Workshop on Innovative Ingredient Technologies to Enhance Iron Absorption Mar 09-12. Washington, DC: Verlag Hans Huber.

26. Hallberg L, Brune M \& Rossander L (1986) Effect of ascorbic acid on iron absorption from different types of meals: studies with ascorbic-acid-rich foods and synthetic ascorbic acid given in different amounts with different meals. Hum Nutr Clin Nutr 40A, 97-113.

27. Cook JD (2005) Diagnosis and management of irondeficiency anaemia. Best Pract Res Clin Haematol 18, 319-332.

28. Gibson RS (2005) Principles of Nutritional Assessment, 2nd ed. New York: Oxford University Press.

29. Baynes RD (1996) Assessment of iron status. Clin Biochem 29, 209-215.

30. Ballot D, Baynes RD, Bothwell TH, et al. (1987) The effects of fruit juices and fruits on the absorption of iron from a rice meal. Br J Nutr 57, 331-343.

31. Commonwealth Department of Health and Ageing Australia, Ministry Of Health New Zealand \& National Health and
Medical Research Council (2006) Nutrient Reference Values for Australia and New Zealand Including Recommended Dietary Intakes. Canberra: Commonwealth of Australia and New Zealand Government.

32. Zimmerman $\mathrm{MB}$, Winichagoon $\mathrm{P}$, Gowachirapant $\mathrm{S}$, et al. (2005) Comparison of the efficacy of wheat-based snacks fortified with ferrous sulfate, electrolytic iron, or hydrogenreduced elemental iron: randomized, double-blind, controlled trial in Thai women. Am J Clin Nutr 82, 1276-1282.

33. Cook JD, Reddy MB, Burri J, et al. (1997) The influence of different cereal grains on iron absorption from infant cereal foods. Am J Clin Nutr 65, 964-969.

34. Hallberg L, Brune M, Erlandsson M, et al. (1991) Calcium: effect of different amounts on nonheme- and heme-iron absorption in humans. Am J Clin Nutr 53, 112-119.

35. Minehane A \& Fairweather-Tait S (1998) Effect of calcium supplementation on daily nonheme iron absorption and long term iron status. Am J Clin Nutr 68, 96-102.

36. Bendich A (2001) Calcium supplementation and iron status of females. Nutrition 17, 46-51.

37. Hallberg L, Brune M \& Rossander L (1989) Iron absorption in man: ascorbic acid and dose-dependent inhibition by phytate. Am J Clin Nutr 49, 140-144.

38. Hurrell RF, Juillerat MA, Reddy MB, et al. (1992) Soy protein, phytate, and iron absorption in humans. Am J Clin Nutr $\mathbf{5 6}$ $573-578$

39. Kristensen MB, Tetens I, Jorgensen ABA, et al. (2005) A decrease in iron status in young healthy women after long-term daily consumption of the recommended intake of fibre-rich wheat bread. Eur J Nutr 44, 334-340.

40. Hanson LN, Engelman HM, Lee Alekel D, et al. (2006) Effects of soy isoflavones and phytate on homocysteine, C-reactive protein, and iron status in postmenopausal women. $A m J$ Clin Nutr 84, 774-780.

41. Hurrell RF (1997) Preventing iron deficiency through food fortification. Nutr Rev 55, 210-222.

42. World Health Organization (2001) Iron Deficiency Anaemia: Assessment, Control and Prevention. A Guide for Programme Managers. Geneva: WHO.

43. Galloway R \& McGuire J (1994) Determinants of compliance with iron supplementation - supplies, side-effects, or psychology. Soc Sci Med 39, 381-390.

44. Skikne BS, Flowers CH \& Cook JD (1990) Serum transferrin receptor - a quantitative measure of tissue iron deficiency. Blood 75, 1870-1876. 